\title{
Secure mine water use with compliant discharge
}

\author{
$\underline{\text { Lei Gao }}^{\text {a }}$, Damian Barrett ${ }^{\text {b }}$, Yun Chen ${ }^{\text {b }}$, Xiangfeng Zhang ${ }^{\text {a, c }}$, Susan Cuddy ${ }^{\text {b }}$, Mingwei Zhou ${ }^{\text {d, }}$ \\ Zahra Paydar ${ }^{\mathrm{b}}$, and Luigi Renzullo ${ }^{\mathrm{b}}$ \\ ${ }^{a}$ CSIRO Water for a Healthy Country National Research Flagship, CSIRO Land and Water, Glen Osmond, \\ South Australia, Australia \\ ${ }^{b}$ CSIRO Water for a Healthy Country National Research Flagship, CSIRO Land and Water, Canberra, \\ Australian Capital Territory, Australia \\ ${ }^{c}$ School of Electrical Engineering, Shanghai Dianji University, Minhang District, Shanghai, China \\ ${ }^{d}$ CSIRO Ecosystem Sciences, Highett, Victoria, Australia \\ Email addresses: lei.gao@csiro.au
}

\begin{abstract}
Water is of great need by a broad range of mining activities, and is becoming more valuable due to growing demand and increasing scarcity. Following years of dry conditions, most mines in Queensland, Australia have been designed to highly reuse water and catch as much runoff as possible. However, during significant rainfall periods, unregulated mine water discharge may result in significant external environmental impacts, which lead mine water managers to reconsider the water management strategies. In particular, a careful balance needs to be struck between securing a 'fit-for-purpose' water use during water limited periods, on one hand, and reducing the risk of unregulated discharges from mine sites when water is in excess, on the other.

A solution suggesting that actively regulated discharge can be used to reduce the risk of occurrence of unregulated discharge has been placed at the disposal of mine water managers. The study aims to examine the feasibility of the solution. To do this, we used a system model called SMART to produce the trade-offs between securing water for mine production and minimising unregulated discharge. The model combines a simulator of mine water use and a multi-objective optimisation scheme. We applied the system model into a coal mine in the Fitzroy Basin, Queensland, Australia. The results demonstrate that unregulated discharges can be significantly reduced in the case study mine site. The successful use of mine water management strategies, such as formulating discharge regulations, requires a tool capable of providing scientific advice. Models similar to the one used in this paper can assist mine water managers in finding more balanced strategies under multiple management objectives.
\end{abstract}

Keywords: mine water management, modelling mine water use, water resources management, mining, multi-objective optimisation, unregulated discharge 


\section{INTRODUCTION}

Water is of great need by a broad range of mining activities, such as mineral processing, machine cooling, dust control, drilling, and human consumption. The locations of mine sites are usually remote and arid, making water demand even more significant. In addition, rapid increase in production, intensifying competition with other water users, and significant climate variability have brought a pressure of securing water use to the mining industry. Especially after years of drought, most mines in Queensland, Australia have been designed to have storages for fresh water and worked water (contaminated or mine-affected water), in order to fully utilise water and catch as much runoff as possible. However, this may lead to significant external environmental impacts expressed through unregulated discharge of worked water during excess supply periods. Unregulated discharge here refers to unpermitted discharge of worked water into the environment, which is usually caused by significant rainfall. The discharge might put the livelihood of community and the environment at risk. The negative impacts of mine discharge have been witnessed in recent flooding periods. For example, in 2010/2011, discharge from flooded mine sites in the Fitzroy Basin in Queensland resulted in a much higher mortality rate of marine species and potential health issues of local community. So a mine water system must be redirected to achieve dual competing goals: (1) ensuring water security at a quality that is 'fit-for-purpose' during water limited periods, and (2) reducing the risk of unregulated discharges from mine sites when water is in excess.

The unregulated discharge we considered in this paper is the overflow from a worked water store due to continuous and heavy rain. Mine water managers are advised of a means to address the dual goal problem through exploring strategies on actively regulated discharge. Conceptually, such strategies might exist to diminish the risk of occurrence of unregulated discharge by doing regulated discharge in advance. This paper aims at testing the feasibility of the solution. To do this, we built a system model called SMART, which embeds a simulator of mine water use within a multi-objective optimisation scheme to produce the trade-offs between two conflicting objectives - securing water for mine production and minimising unregulated discharge whose quality sometimes is at an unacceptable level.

The case study is a coal mine, which is located in the Fitzroy Basin, Queensland, Australia. It supplies quality coal for both domestic and international markets. The application of our system model is built on readily published regulations and available data, and is able to provide scientific basis for advising mine water managers on management strategy development associated with worked water discharge. The rest of paper is organized as follows. Section 2 introduces the conceptual model and the system model. A coal mine is used as a case study. The results from the case study are presented in Section 3 . The final section concludes the paper.

\section{SYSTEM MODEL}

To enable the assessment of mine water management strategies, we proposed an object-oriented system model called SMART that includes two main components: a simulation of mine water system and a multiobjective optimisation framework. The conceptual model of the mine water system is depicted in Figure 1 and will be briefly introduced in this section. As shown in the figure, the mine water system model consists of some objects: one raw water store, one worked water store, and several water tasks. Water quantity and quality on a mine site are modelled as a function of rainfall, runoff, evaporation, seepage and water use in production. We refer the reader to (Gao et al., 2013a) for more details about the simulation component. Overflows from the worked water store (here referred as unregulated discharge) can negatively affect local environment and water resources. But the potential environmental threat posed by unregulated discharge could be mitigated by actively releasing mine-affected water to receiving waters/streams (referred as regulated discharge). The regulated discharge is limited to times of natural flow events, release rates, and discharge water quality criteria. The release of mine-affected water to waters must only take place during periods of natural flow events in accordance with the receiving water flow criteria for discharge. 


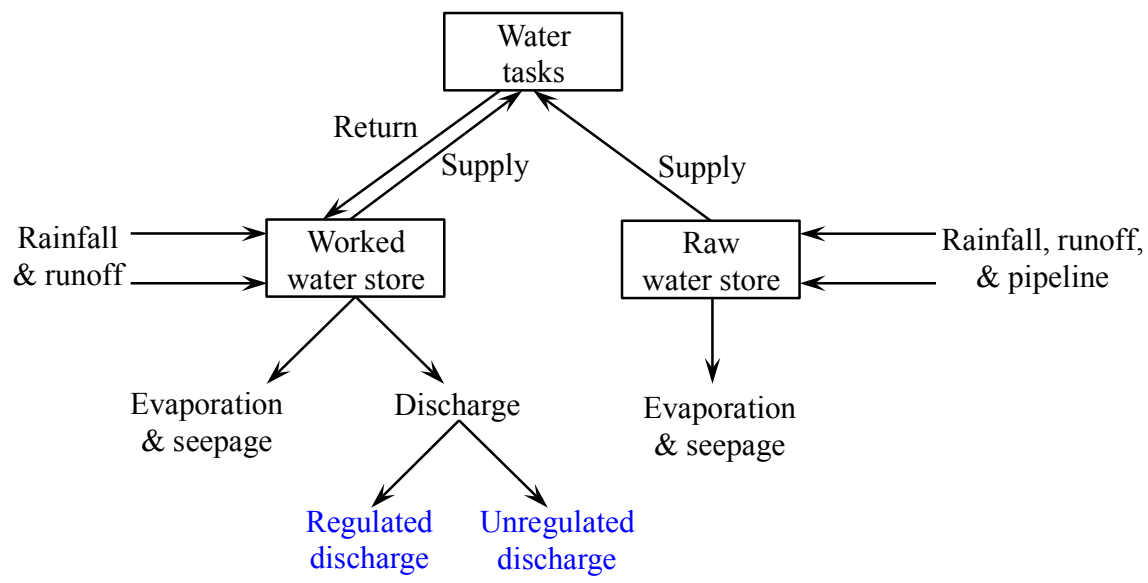

Figure 1. Simplified view of the water system in the study mine site.

In order to enable the investigation of optimal water management strategies, we embedded the simulation model of SMART into an optimisation framework named jMetal (Durillo and Nebro, 2011), as shown in Figure 2 .

Figure 2. jMetal-based SMART framework.

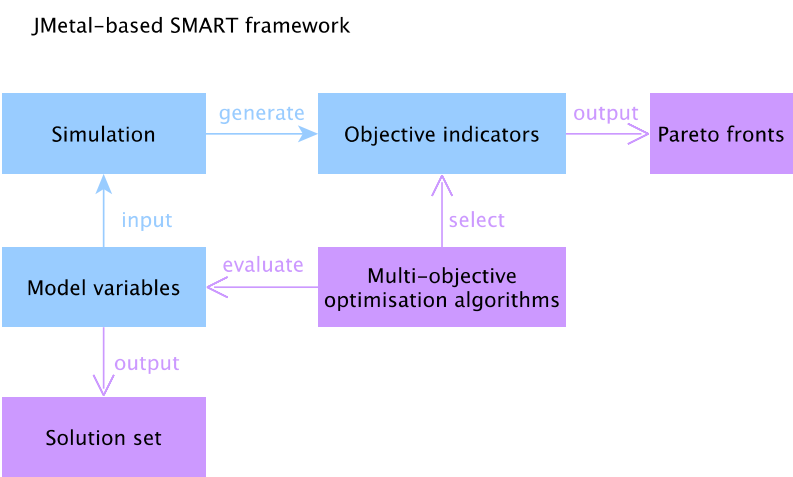

As shown in Figure 2, the jMetal-based SMART framework includes a simulation model (represented in blue) with some model variables to be investigated, and one or more multi-objective algorithms (represented in purple) to search the variable space. jMetal regards the SMART simulation component as its Problem object and select potential solutions through evaluating their objective indicators provided by the simulation component. jMetal inputs a set of selected variables into the simulation component at each iteration, evaluates candidate solutions against multiple objectives, and collects qualified solutions and the corresponding Pareto fronts. The dual goal problem in this paper can be formulated as a vector of two functions that maps $m$ decision variables (parameters) to the two objectives:

$$
\begin{array}{cl}
\text { Minimise } & \mathrm{y}=F(x)=\left(f_{f r}(x), f_{u d}(x)\right)^{T} \\
\text { Subject to } & x=\left(x_{1}, x_{2}, \ldots, x_{m}\right) \in X \\
& y=\left(y_{f r}, y_{u d}\right) \in Y
\end{array}
$$

where $x$ is the decision vector, $f_{f r}(x)$ is the objective function of failure rate that water stores are not able to offer acceptable supply to water tasks, $f_{u d}(x)$ is the objective function of volume of unregulated discharges that represents accumulative overflows from the worked water store over a simulation period, $X$ is the parameter space, $y$ is the objective vector, and $Y$ is the objective space.

\section{CASE STUDY}

In the case study coal mine, a storage facility for worked water has been constructed and may release its excess water to the receiving river along with the mine site. However, the mine affected water release (regulated discharge) is subject to regulatory requirements and standard criteria. A set of model water conditions have been developed in relation to coal mines located within the basin (DEHP, 2013), and the 
conditions may be further applied to elsewhere in Australia. Different discharge conditions in low, medium, and high receiving water flows are included in the water conditions guideline.

The historical stream discharge data at the nearby gauging station in the receiving river was obtained from Water Monitoring Data Portal (available at http://watermonitoring.derm.qld.gov.au/host.htm). The mine affected water release criteria during flow events is shown in Table 1. The simulation period is from July 1, 2001 to June 30, 2012, including a prolonged dry period and a similar length wet period.

Table 1. Mine affected water release criteria during flow events in the case study mine.

\begin{tabular}{cccc}
\hline Condition id & $\begin{array}{c}\text { Minimum receiving water flow } \\
\text { criteria for discharge }\left(\boldsymbol{m}^{\mathbf{3}} / \boldsymbol{s}\right)\end{array}$ & $\begin{array}{c}\text { Maximum release } \\
\text { rate }\left(\boldsymbol{m}^{3} / \boldsymbol{s}\right)\end{array}$ & $\begin{array}{c}\text { Electrical Conductivity } \\
\text { Limit }(\boldsymbol{\mu} \boldsymbol{S} / \mathbf{c m})\end{array}$ \\
\hline$(1)$ & 5 & 0.15 & 3500 \\
$(2)$ & 20 & 0.26 & 7500 \\
$(3)$ & 50 & 1 & 5000 \\
$(4)$ & 100 & $2($ or 1.3$)$ & $5000($ or 7500$)$ \\
\hline
\end{tabular}

The simulation model was calibrated in terms of a number of objectives using the proposed multi-objective optimisation framework. In summary, on condition that ensuring normal coal production, the calibration makes the water demand for each water task, the wet indicator ( $\%$ time above $90 \%$ full) and the dry indicator ( $\%$ time below $25 \%$ full) in the worked water store, and discharge per unit of coal production be close to the corresponding reported indicators. We assumed there is no regulated discharge so that only unregulated discharges occur in the calibrated model (the baseline model). The worked water store volume, unregulated discharge from the worked water store, river stream flow, and electrical conductivity of worked water in the baseline scenario are shown in Figure 3.

As shown in Figure 3, the effect of rainfall is clearly distinct in the time series of worked water store volume, unregulated discharge, river stream flow events, and conductivity of the worked water store. The volume in the worked water store decreases during the period when there are relatively fewer large rainfall events and increases following each of the major rainfall events. The dynamics of conductivity act conversely to the volume. For example, during the large rainfall events in late 2010 and early 2011 , the water exceeded the worked store and resulted in heavy unregulated discharge, while the conductivity decreased to the level below $3500 \mu \mathrm{S} / \mathrm{cm}$. The conductivity dynamics in the worked water store in response to rainfall coincide well with the experiments by Vink et al. (2009). 

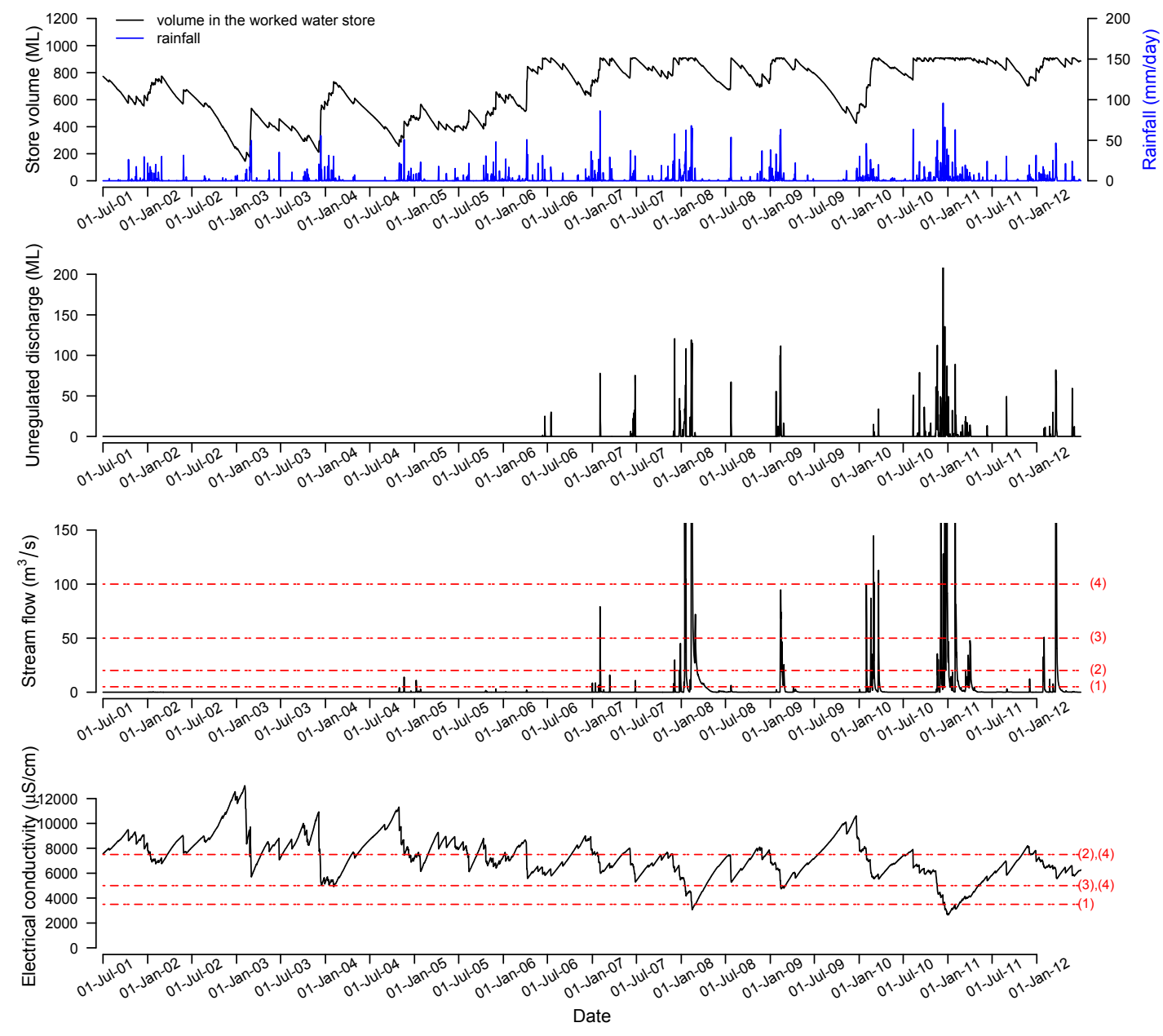

Figure 3. Worked water store volume, unregulated discharge from the worked water store, river stream flow, and electrical conductivity of worked water in the baseline scenario. The red dot lines represent the condition levels of mine affected water release criteria shown in Table 1.

To diminish the failure times of water supply and the unregulated discharges, we experimented with five optimisation strategies. Optimisation strategy 1 only has one variable, which represents a safe level in the worked water storage that balances keeping a sufficient amount of water to supply tasks while at the same time ensuring sufficient freeboard exists to accommodate rainfall events of particular size. Optimisation strategy 2 includes two variables, representing safe levels for dry and wet periods in a year. Optimisation strategies 3 and 4 include four and twelve variables, representing safe levels for four seasons and twelve months in a year, respectively. Optimisation strategy 5 has two variables, representing safe levels for dry years and wet years during the simulation period. The Pareto fronts for the five scenarios are shown in Figure 4, which presents trade-offs between two objectives - number of failure times of water supply and the cumulative volume of unregulated discharges. We can see that, for optimisation strategy 1 , there are a set of choices that are Pareto efficient, while for the rest of optimisation strategies, the Pareto Fronts converge to one choice. The optima are found using the comprehensive learning particle swarm optimiser for multiobjective optimisation improved from previous work (Gao and Hailu, 2010; Huang et al., 2006). The optimal choice from optimisation strategies 2-5 outperforms the choices from optimisation strategy 1 in terms of both objectives. The optimal choice represents that, on condition that ensuring normal coal production, the accumulative volume of unregulated discharges has been reduced by approximately $85 \%$, from 4374 ML to $666 \mathrm{ML}$ during the simulation period, compared to the baseline scenario. The performance of the optimal solution (the outcome from optimisation strategy 5) is shown in Figure 5. 
Gao et al., Secure mine water use with compliant discharge

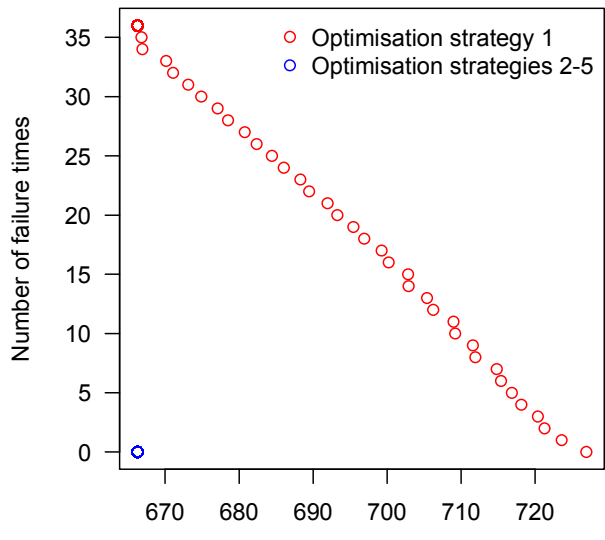

Sum of unregulated discharges (ML)

Figure 4. Pareto fronts of five experimental optimisation strategies.

Figure 5. Worked water store volume, unregulated discharge from the worked water store, river stream flow,
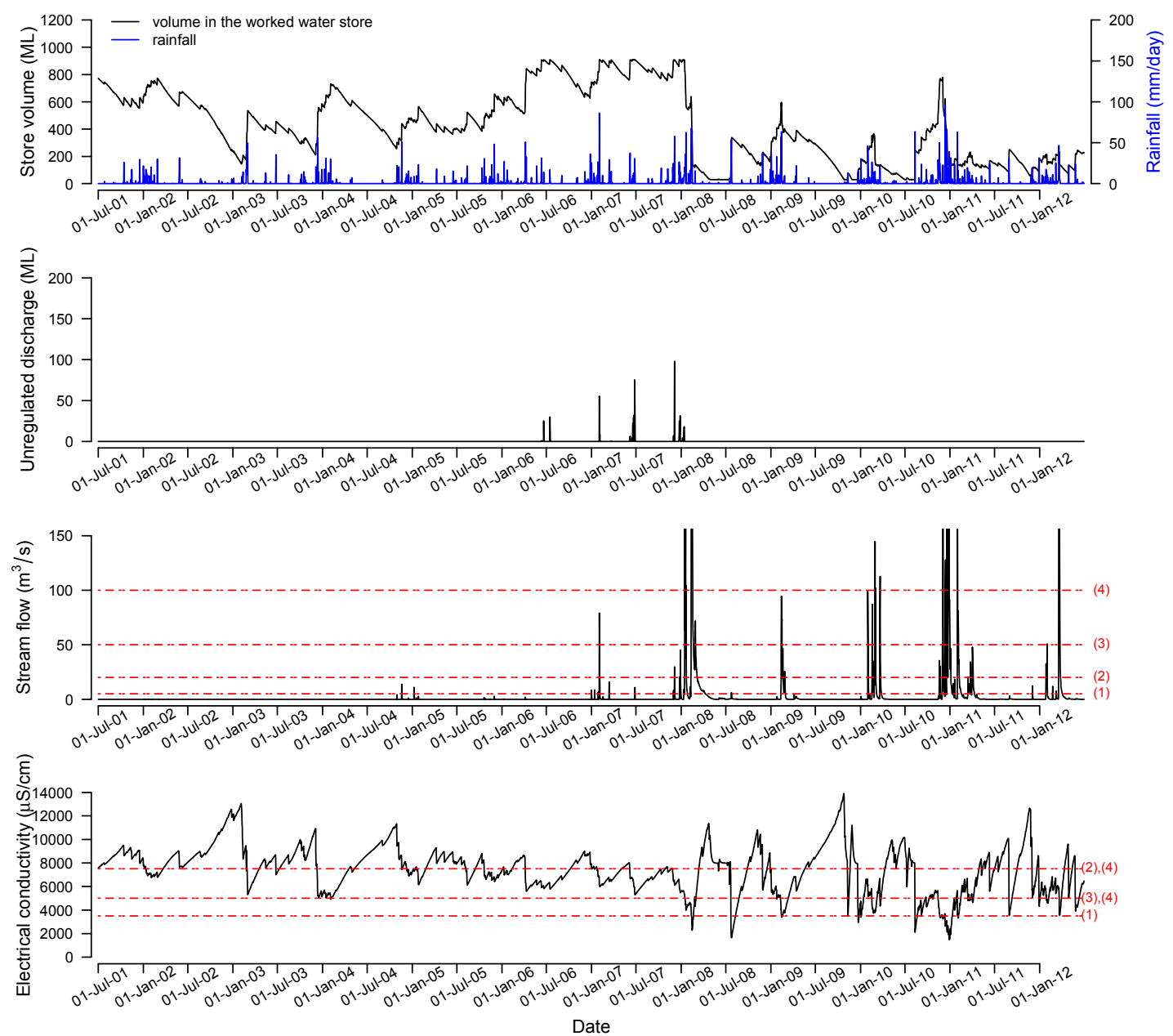

and electrical conductivity of worked water in the optimal scenario. The red dot lines represent the condition levels of mine affected water release criteria shown in Table 1.

The reasons why the unregulated discharges cannot be minimised any more under the experimented optimisation strategies are multifold. Some unregulated discharges occur before natural flow triggers, for example the ones near July 1, 2006. The discharge water quality also restricts the release of some worked water, for example some unregulated discharges in February 2007 are partly offset by regulated actions in condition (2), although the corresponding natural flow trigger reaches condition (3). 


\section{CONCLUSIONS}

The work presented in this paper evaluates the effect of actively regulated discharge on diminishing unregulated discharges caused by overflows from the worked water store. The results from a simulation and optimisation model demonstrate that the unregulated discharges can be significantly reduced in the case study mine site. However, the performance is achieved with historical data. Future work includes two directions: one is to develop a Markov chain switching model on climate prediction (Gao et al., 2013b), with which we can test the performance reliability of each optimisation strategy in the future climate; the other is to explore control theory methods as a means of determining optimal trajectories of storage given seasonal rainfall forecasts from the Bureau of Meteorology.

\section{ACKNOWLEDGMENT}

This work is supported by the Australian Coal Association Research Program as project 51088 and CSIRO Water for a Healthy Country Flagship as appropriation research project "Strategic Water Management in Mining". We thank Dr. Russell Crosbie for his help on accessing related research data. A coauthor (Dr. Xiangfeng Zhang) would like to express her gratitude to the support of the Innovation Program of Shanghai Municipal Education Commission (NO.13YZ139).

\section{REFERENCES}

DEHP, (2013). Model water conditions for coal mines in the Fitzroy basin. Department of Environment and Heritage Protection guideline, available at http://www.ehp.qld.gov.au/land/mining/pdf/model-waterconditions-mining-fitzroy-em288.pdf.

Durillo, J.J., Nebro, A.J., (2011). jMetal: A Java framework for multi-objective optimization. Advances in Engineering Software, 42(10), 760-771.

Gao, L., Barrett, D., Chen, Y., Zhou, M., Cuddy, S., Paydar, Z., Renzullo, L., (2013a). A process-based simulation model for strategic mine water management, 20th International Congress on Modelling and Simulation: Adelaide, South Australia.

Gao, L., Connor, J.D., Dillon, P., (2013b). The economics of groundwater replenishment for reliable urban water supply, The 8th Annual International Symposium on Managed Aquifer Recharge: Beijing, China.

Gao, L., Hailu, A., (2010). Comprehensive learning particle swarm optimizer for constrained mixed-variable optimization problems. International Journal of Computational Intelligence Systems, 3(6), 832-842.

Huang, V.L., Suganthan, P.N., Liang, J.J., (2006). Comprehensive learning particle swarm optimizer for solving multiobjective optimization problems. International Journal of Intelligent Systems, 21(2), 209-226.

Vink, S., Moran, C., Golding, S., Baublys, K.A., Nanjappa, V., (2009). Understanding mine site water and salt dynamics to support integrated water quality and quantity management. Mining Technology, 118(3/4), 185-192. 